\title{
Oxygen isotopes in tree rings of Abies alba: The climatic significance of interdecadal variations
}

\author{
Matthias Saurer \\ Paul Scherrer Institute, Villigen, Switzerland \\ Paolo Cherubini \\ Swiss Federal Institute for Forest, Snow and Landscape Research, Birmensdorf, Switzerland \\ Rolf Siegwolf \\ Paul Scherrer Institute, Villigen, Switzerland
}

\begin{abstract}
We determined the $\delta^{18} \mathrm{O}$ variations in the latewood of tree rings from four silver firs (Abies alba Mill.) for the period 1840-1997 at a mountain site in Switzerland, establishing the longest available tree ring record for $\delta^{18} \mathrm{O}$ in central Europe. The isotope ratios were determined on whole wood with a rapid continuous flow pyrolysis technique, thus avoiding cellulose extraction. We found significant correlations with $\delta^{18} \mathrm{O}$ tree ring records from the same region, although these involved different materials (cellulose extracted from whole rings rather than latewood) and different species. This indicates that physical factors are more important than biological influences as a determinant of $\delta^{18} \mathrm{O}$ in tree rings. The isotope tree ring chronology was highly correlated with the oxygen isotope variations in the June/July precipitation for the period 1972-1992 $(r=0.72)$, and $\delta^{18} \mathrm{O}$ in whole wood of tree rings is therefore well suited for the reconstruction of $\delta^{18} \mathrm{O}$ in precipitation. We found a slow, quasi-periodic variation of the $\delta^{18} \mathrm{O}$ series with a periodicity of $\sim 24$ years, which is correlated to variations in the July temperature. This could be caused by fluctuations in the large-scale atmospheric circulation over Europe and the North Atlantic, which may result in a change in source and flow path of atmospheric moisture, affecting the isotope ratio of precipitation in Switzerland. Although a significant correlation with summer temperature was found $(p<0.01)$, the low correlation coefficient $(r=0.31)$ indicates that the $\delta^{18} \mathrm{O}$ variations cannot be explained by temperature variations alone. However, even when considering that the factors influencing $\delta^{18} \mathrm{O}$ in precipitation are not yet fully understood, our study shows the potential of tree rings to provide long records of $\delta^{18} \mathrm{O}$ in precipitation for continental areas, which will improve our understanding of the causes of natural perturbations of the climate system.
\end{abstract}

\section{Introduction}

Variations in the oxygen isotope ratio of water and organic matter have long been recognized as a valuable tool in climate research. Ice cores, sea sediments, and tree rings are natural archives for oxygen over various timescales and time resolutions [Hoefs, 1987]. Significant climatic changes, such as the glacial to Holocene transition, are reflected in a drastic change in the oxygen isotope ratio. The analysis of $\delta^{18} \mathrm{O}$ from recent meteoric water showed that in middle and high latitudes the temperature at the location of the precipitation is probably the most important determinant of the isotope ratio but also that the source of moisture, the atmospheric circulation pattern, and the continentality play an important role [Rozanski et al., 1993]. The spatial relation of $0.7 \%{ }^{\circ} \mathrm{C}$ [Dansgaard, 1964] for the

Copyright 2000 by the American Geophysical Union.

Paper number 2000JD900160. 0148-0227/00/2000JD900160\$09.00 dependence of $\delta^{i 8} \mathrm{O}$ in precipitation on temperature has often been used for interpreting temporal variations of $\delta^{18} \mathrm{O}$ at a fixed location. Recently, however, some evidence has been presented against this assumption [Jouzel et al., 1997]. Over longer timescales, factors other than temperature may be important in explaining the variations in $\delta^{18} \mathrm{O}$, in particular, changes in large-scale atmospheric circulation. There is still considerable uncertainty about the climatic significance of interdecadal- to century- scale variations in the isotope ratio, mainly because calibration studies during the instrumental period are lacking. This problem is due to the sparseness of the network and the temporal shortness of the available data sets of $\delta^{18} \mathrm{O}$ in precipitation (30-40 years at most) and the remote spatial location of the arctic ice core sites, preventing an unambiguous calibration with meteorological stations [Jones et al., 1993].

Oxygen isotope analysis of tree rings provides an alternative method for the calibration between isotope variations and climate. Forest sites close to meteorological stations are available in most continental areas, and $\delta^{18} \mathrm{O}$ of 
tree ring cellulose is correlated with $\delta^{18} \mathrm{O}$ in precipitation [Burk and Stuiver, 1981; Edwards and Fritz, 1986], reflecting, in particular, the available water during the growing season [Saurer et al., 1997a]. Uncertainty over the use of tree rings in reconstructing $\delta^{18} \mathrm{O}$ arises from the complexity of the transfer function between oxygen in the soil water and oxygen in the cellulose or wood. First, soil water may not ideally reflect the isotopic composition of precipitation because of evaporation, causing a gradient with depth or isotopic inhomogeneity in the soil. This factor is, however, of minor importance in temperate regions (in contrast to arid regions). Second, and most significant, there is an oxygen isotope enrichment in the leaf water due to transpiration. This enrichment can be as high as $20 \%$, depending mainly on the relative humidity of the atmosphere [Dongmann et al., 1974]. Fractionation models have been developed to estimate the ${ }^{18} \mathrm{O}$ enrichment with reasonable precision [Flanagan et al., 1991; Farquhar and Lloyd, 1993]. This isotope enrichment is transferred to sucrose by the exchange of carbonyl atoms of intermediate photosynthates with the chloroplast water [Sternberg and DeNiro, 1983]. Finally, there is an additional alteration of the isotope ratio during the formation of tree rings: Unenriched water in the xylem can exchange part of the sucrose oxygen atoms used to produce the cellulose [Hill et al., 1995], thereby reducing the effect of the leaf water enrichment by a factor of $\sim 2-3$ [Saurer et al., 1997b]. This means that the influence of the relative humidity on the isotope ratio in the tree ring is not as strong as predicted from the leaf enrichment model and that despite the large number of potential factors altering the isotope ratio the $\delta^{18} \mathrm{O}$ of precipitation is the main factor determining the $\delta^{18} O$ of the tree ring cellulose.

In this study, we present a 150-year-long mean chronology of oxygen isotope variations in tree ring latewood from four silver firs (Abies alba Mill.) from a site in Switzerland. The general weather situation at this central European site is dominated by westerly winds from the Atlantic. The isotope ratio of wood at this site may therefore reflect longterm changes in atmospheric circulation over the North Atlantic, as described, for instance, by the North Atlantic Oscillation (NAO) index [Wanner et al., 1997). This paper describes the interdecadal isotope variations in tree rings, and assesses whether they represent isotope variations in precipitation and whether they can be used as proxies for reconstructing past climatic changes. The site is suited to a calibration study because it is located close to a station providing a long meteorological record as well as an IAEA station providing $\delta^{18} \mathrm{O}$ in precipitation since 1972 [IAEA/WMO, 1998] (the IAEA/WMO global network for isotopes in precipitation database is available at http://www.iaea.org/programs/ri/gnip/gnipmain.htm).

Addi-tionally, the site is used as a permanent plot in a research program (the Swiss Long-Term Forest Ecosystem

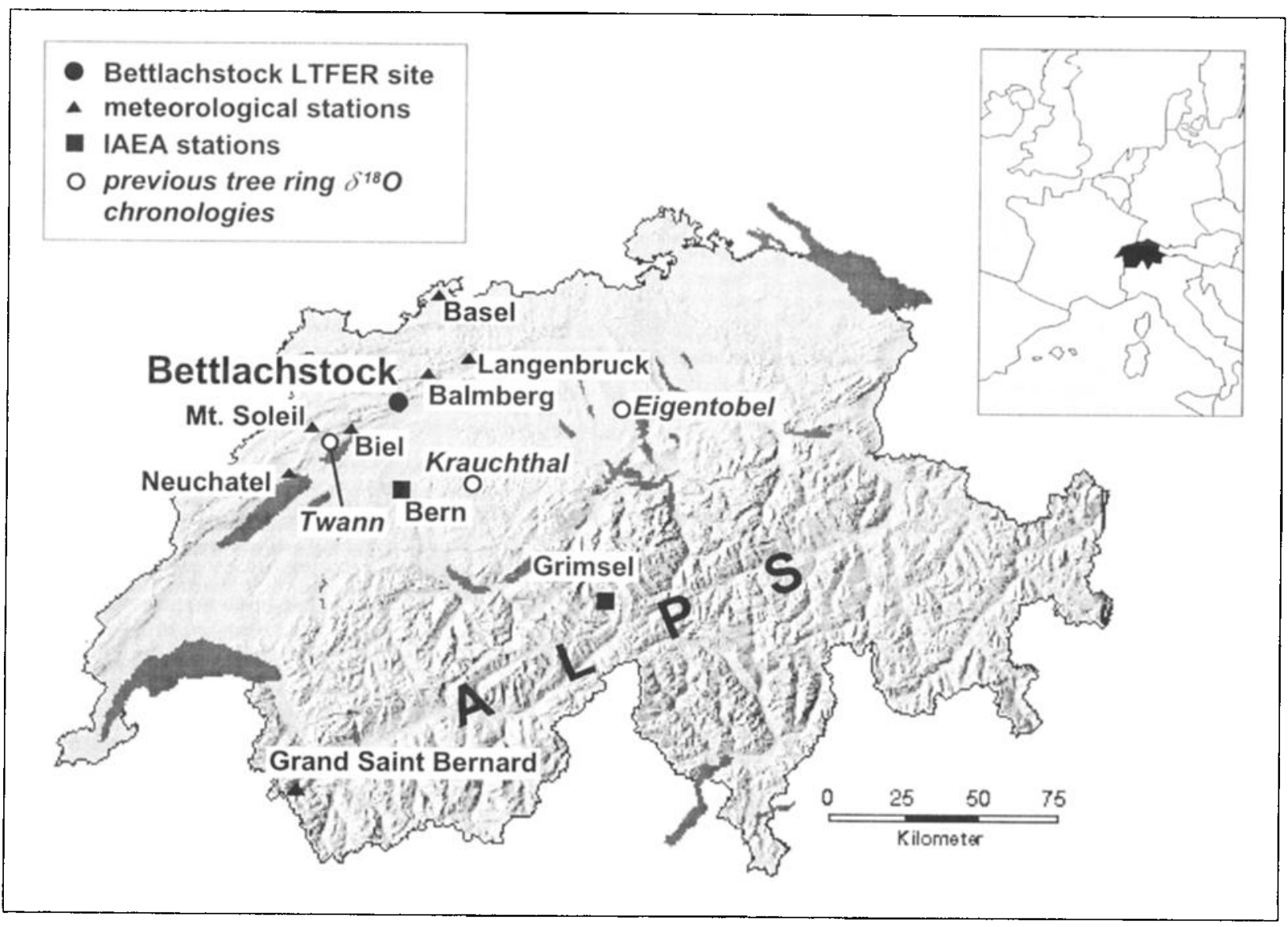

Figure 1. Map of Switzerland showing the study site (Long-Term Forest Ecosystem Research plot "Bettlachstock"), the IAEA stations (Bern and Grimsel), and the meteorological stations and the sites where previous tree ring studies on oxygen isotopes have been carried out [Saurer et al., 1997a; Anderson et al., 1998]. 
Research Program), where many microclimatological and biological parameters are measured, enabling a better understanding of possible climatic or biological effects on the isotope ratio.

\section{Materials and Methods}

\subsection{Site}

The samples were taken at the long-term monitoring plot "Bettlachstock" (Langfristige Waldökosystem-Forschung), which is located close to Solothurn in Switzerland, on a southern slope (gradient $66 \%$ ) of the Jura Mountain chain (1101-1196 $\mathrm{m}$ above sea level (asl); $7^{\circ} 25^{\prime} \mathrm{E}, 47^{\circ} 13^{\prime} \mathrm{N}$; see Figure 1). The stand is a mixed mountain beechwood (Cardamino-Fagetum tilietosum) dominated by Fagus sylvatica L. and with Abies alba Mill., Picea abies (L.) Carst., Acer pseudoplatanus L., Fraxinus excelsior L., and Ulmus glabra Huds. The soil types are Rendzic Leptosols and Calcaric Cambisols, and the humus forms are vermimull and mullmoder. The average annual precipitation (1974-1995) at the nearest meteorological station (Balmberg, located at $1075 \mathrm{~m}$ asl, $\sim 11 \mathrm{~km}$ from the site) is $1454 \mathrm{~mm}$. The mean annual temperature is $8.3^{\circ} \mathrm{C}$.

\subsection{Sampling and Sample Preparation}

In April 1998, four dominant silver fir trees (Abies alba) were sampled by taking three to four cores at breast height $(1.3 \mathrm{~m})$, using an increment borer $0.5 \mathrm{~cm}$ in diameter. Tree rings were dated with the help of a stereo microscope (Wild M3Z Leica, Germany). One core from each tree was mounted on channeled wood, sanded, and used for ring width measurement. This core was not used for isotope analysis, as the preparation for ring width measurement might have affected wood isotopic ratio. Ring width measurements were made to the nearest $0.01 \mathrm{~mm}$ on the cores, using Time Series Analysis and Presentation (TSAP) measurement equipment and software package (Frank Rinn, Heidelberg, Germany). The results were examined using the DENS-software package (Swiss Federal Institute for Forest, Snow and Landscape Research, WSL, Birmensdorf, Switzerland). The raw ring widths of the single curves of each dated tree were plotted. The single curves were checked visually and then synchronized by the Gleichläufigkeit technique (there is no English equivalent to this term), which is a measure of the year-to-year agreement between the interval trends of two chronologies based on the sign of agreement and Student's t test, which determines the degree of correlation between the curves.

The other cores were dated, and one core per tree was used for isotopic analysis. The latewood and the earlywood were separated from the core with a razor using a stereo microscope (40X magnification). The latewood/earlywood boundary was clearly visible, and therefore separation was straightforward. The latewood of the four trees was pooled for each year prior to further analysis to reduce the amount of work. This "pooling method" has been shown to yield a reliable mean isotope curve of several trees [Borella et al., 1998]. For homogenization the latewood samples were milled (Ultrazentrifugalmühle ZM1000, Retsch, Germany). Previous results from a comparison of $\delta^{18} \mathrm{O}$ in tree ring wood and cellulose suggested that whole wood might be suitable for climate reconstruction [Borella et al., 1999]. Therefore, there was no chemical treatment of the wood.

\subsection{Isotope Analysis}

The ${ }^{18} \mathrm{O} /{ }^{16} \mathrm{O}$ ratio was determined with an on-line pyrolysis system [Saurer et al, 1998] consisting of an elemental analyzer (EA 1108, Fisons, Italy) coupled to an isotope ratio mass spectrometer (delta-S, Finnigan MAT, Germany). The samples $(1.5 \mathrm{mg})$ were loaded in tin capsules and dropped in the pyrolysis tube $\left(1080^{\circ} \mathrm{C}\right.$, filled with glassy carbon) under a helium stream of $150 \mathrm{~mL} / \mathrm{min}$. After the pyrolysis, the oxygen of the sample was found mainly as $\mathrm{CO}$ and was analyzed for the mass ratio 30/28. The amount of oxygen found as $\mathrm{CO}_{2}$ was below $5 \%$ and did not significantly affect the reproducibility of the method. Impurities (e.g., $\mathrm{N}_{2}$ ) were separated from the $\mathrm{CO}$ with a molecular sieve $5 \mathrm{~A}$, whereas traces of water and $\mathrm{CO}_{2}$ were removed with chemical adsorbants (Microanalysis, United Kingdom). Each sample was compared to an internal $\mathrm{CO}$ standard gas, whereas calibration versus VSMOW was done by comparing with a standard cellulose analyzed with the nickel tube pyrolysis method [Saurer et al., 1998]. The results are given in the $\delta$ notation, i.e., $\delta^{18} \mathrm{O}_{\text {Sample }}=$ $\left[\left({ }^{18} \mathrm{O} /{ }^{16} \mathrm{O}_{\text {Sample }}\right) /\left({ }^{18} \mathrm{O} /{ }^{16} \mathrm{O}_{\text {vsmow }}\right)-1\right] 1000(\%)$. The standard deviation for repeated analyses of a standard cellulose was $0.2 \%$.

\subsection{Statistics}

Spectral characteristics of the $\delta^{18} \mathrm{O}$ tree ring series were determined with power spectrum analysis, whereby the Fourier transform of the autocovariance function was calculated using a Hamming window as filter. The background level was estimated by fitting a theoretical red noise to the tree ring spectral density curve (based on the autocorrelation of the tree ring series). This enables the calculation of significance levels using a $\chi^{2}$ test [Schönwiese, 1992].

\section{Results}

The latewood $\delta^{18} \mathrm{O}$ chronology from Bettlachstock is shown in Figure 2a. There is considerable variability, with values ranging from about $21 \%$ to $26 \%$. The extreme minima are found in the years 1888,1957 , and 1973. These data are measured on whole wood (not cellulose), and the values are consistently lower compared to tree ring cellulose data from the same region [Saurer et al., 1997a; Anderson et al., 1998]. The offset between cellulose and whole wood is $\sim 5 \%$. We made crosswise correlation analysis between the Bettlachstock data and the data from the previous studies and found that most relationships between the sites are significant (Table 1; see also Figure 1 for the location of the sites). These results must be considered in relation to previous studies being on a shorter period and involving different material. The data by Saurer et al. [1997a] are based on cellulose of beech trees (Fagus sylvatica), whereas Anderson et al. [1998] used the cellulose of Norway spruce (Picea abies). Furthermore, both studies rely on whole tree ring analysis rather than on the latewood (i.e., the latewood was not separated from earlywood). 

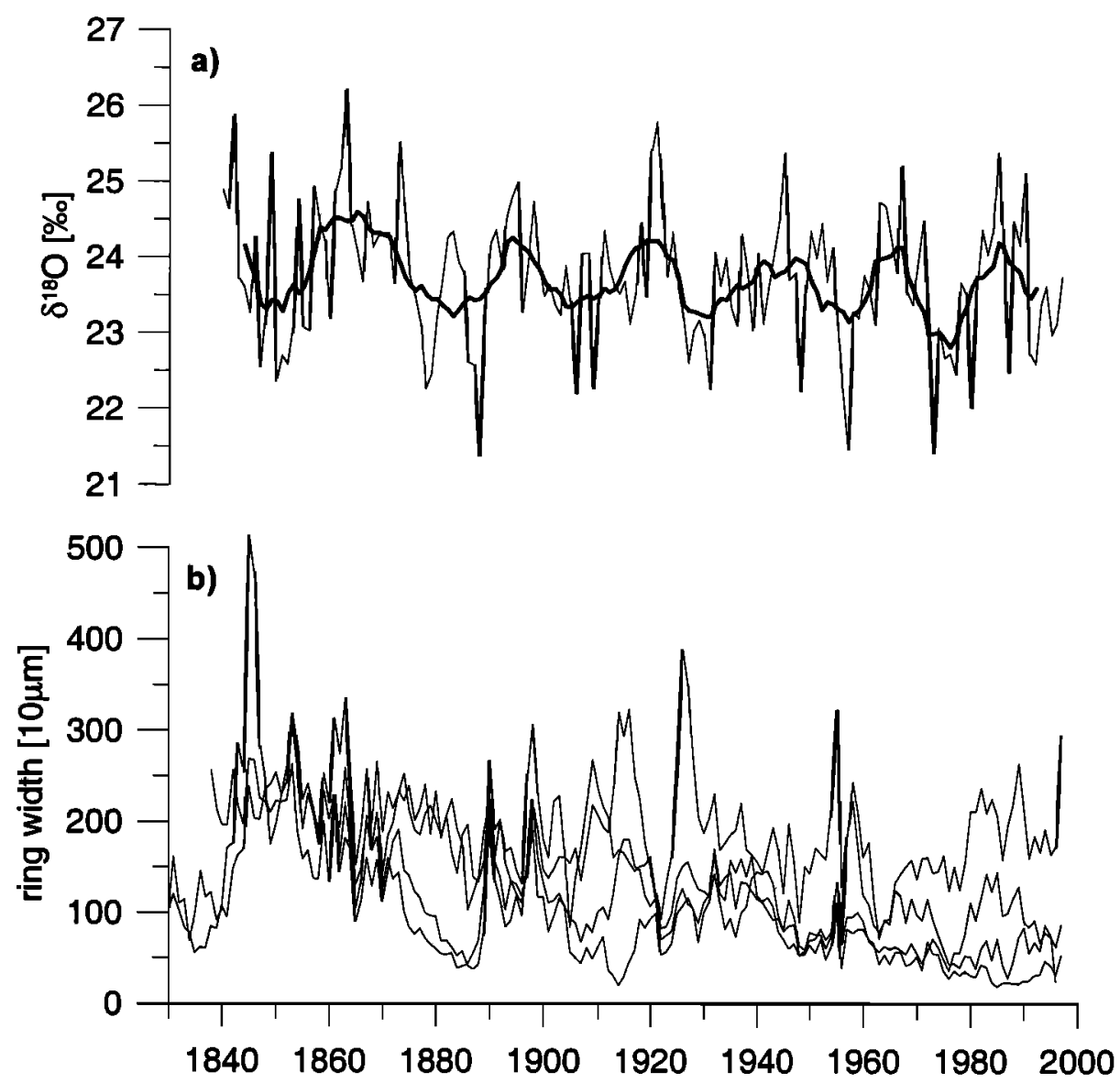

Figure 2. (a) The $\delta^{18} \mathrm{O}$ curve of single-year values (latewood) of Abies alba from Bettlachstock, built as the mean of four trees from the same site. The 10-year running mean is shown. (b) Tree ring width of the four trees used for the isotope study.

The single tree curves of raw ring width measurements for all the sample trees are presented in Figure 2b, whereby the first considered year for the four investigated trees was $1830,1830,1838$, and 1862 . The germination date may roughly be estimated to be 10 years earlier and therefore the trees were $\sim 150-180$ years old. Cross-dating was successful, as indicated by the high degree of common vari- ance in some periods (e.g., 1860-1865) and the synchronous occurrence of pointer years, i.e., extreme narrow or wide rings. All trees show synchronous pointer years (e.g., $1860-1870,1896,1922,1956$, and 1976), and some years (e.g., 1956) can be related to extreme climatic (e.g., frost) events. All trees show an age trend, but the tree ring patterns are very different for each tree, and no synchronous

Table 1. Crosswise Correlation Showing the Relationship Between Tree Ring $\delta^{18} \mathrm{O}$ Curves From Different Sites on the Swiss Central Plateau

\begin{tabular}{|c|c|c|c|c|}
\hline & $\begin{array}{l}\text { Bettlachstock } \\
1840-1997\end{array}$ & $\begin{array}{l}\text { Krauchthal } \\
1971-1992\end{array}$ & $\begin{array}{l}\text { Twann } \\
1935-1986 \\
\text { (3-year means) } \\
\end{array}$ & $\begin{array}{l}\text { Eigentobel } \\
1913-1995\end{array}$ \\
\hline Bettlachstock & 1 & $0.59(n=22)^{*}$ & $0.35(n=18)$ & $0.28(n=82) \dagger$ \\
\hline Krauchthal & & 1 & $0.65(n=5)$ & $0.71(n=22) \dagger$ \\
\hline Twann & & & 1 & $0.77(n=18) \dagger$ \\
\hline Eigentobel & & & & 1 \\
\hline
\end{tabular}

The data from Krauchthal and Twann are from Saurer et al. [1997a] and span the periods from 1971 to 1992 and 1935 to 1986 , respectively; the data from Eigentobel are from Anderson et al. [1998] from 1913 to 1995; and the data from Bettlachstock are from this study. The correlation coefficient $r$ of the linear regression is indicated, whereby the number of common data for each comparison is given in parentheses (n).

* Correlation $\mathrm{p}<0.01$.

$\dagger$ Correlation $\mathrm{p}<0.001$. 


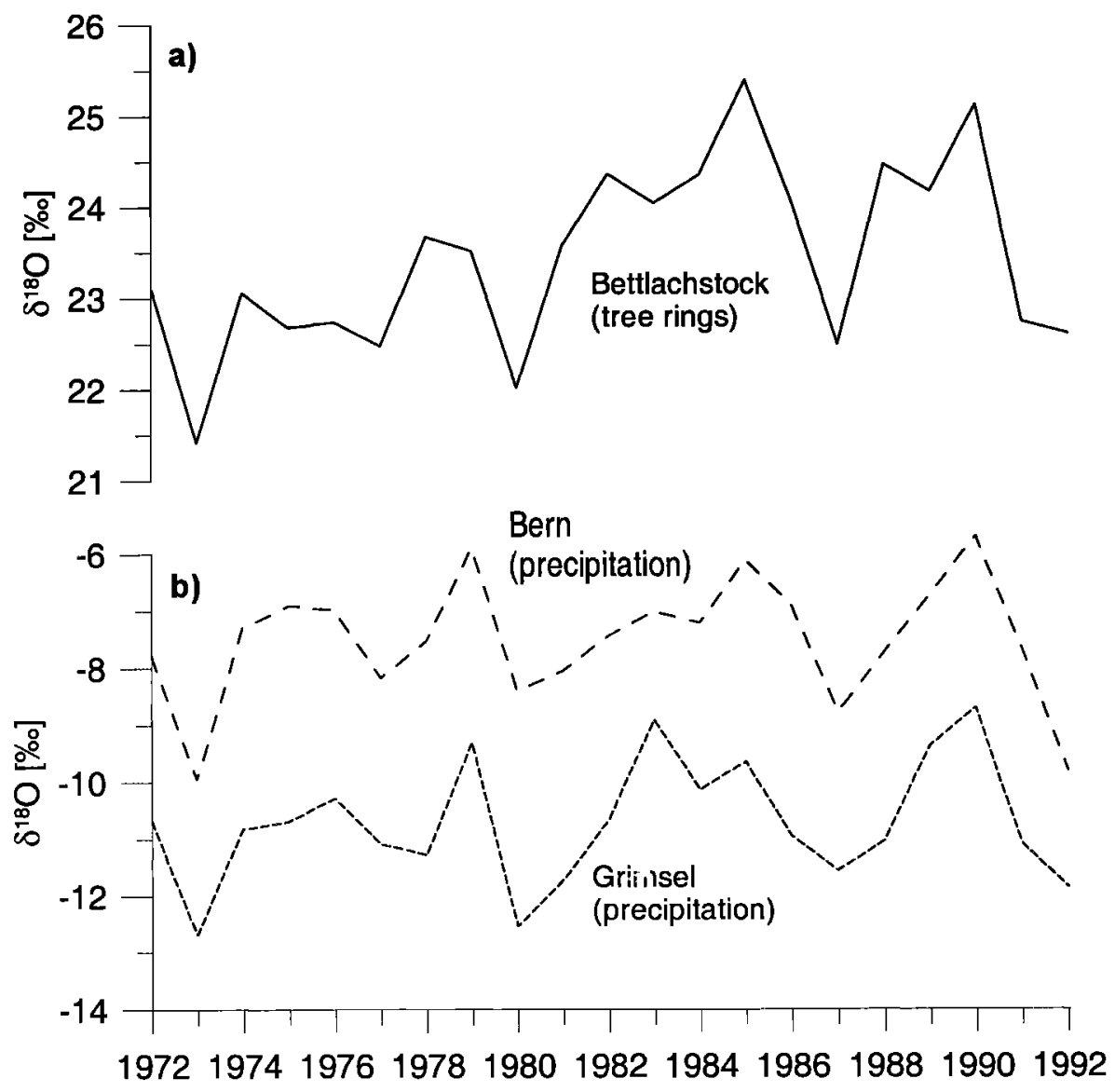

Figure 3. (a) Tree ring $\delta^{18} \mathrm{O}$ chronology for the period 1972-1992. (b) Mean $\delta^{18} \mathrm{O}$ of the precipitation of June and July at the stations Bern and Grimsel for the same period.

abrupt changes are present. This means that trees were growing under competition in the stand. No major disturbance occurred, as no abrupt growth release after suppression was detected, which might be induced by forest management practices. This was also confirmed by a tree ring study of a larger set of samples for this site (data not shown). The influence of silvicultural treatments on tree ring patterns at this site can therefore be excluded. Furthermore, comparing the isotope and the ring width chronologies, no significant correlation was found between ring width and isotope ratio. No synchronous occurrence of extreme values was found.

There are monthly data for $\delta^{18} \mathrm{O}$ in precipitation available from several Swiss stations for the period 1972-1992 ([IAEA/WMO, 1998]; data for Switzerland measured by the Physics Institute, University of Bern). We compared the $\delta^{18} \mathrm{O}$ tree ring series from Bettlachstock with the closest IAEA station (Bern, $511 \mathrm{~m}$ asl) and with a high-altitude IAEA station (Grimsel, $1950 \mathrm{~m}$ asl; see Figure 1). The results are shown in Figure 3. There is a very good agreement between the tree ring isotopes and the June/July variations in $\delta^{18} \mathrm{O}$ of precipitation for both Bern and Grimsel ( $r=0.723$ and 0.717 , respectively). The time course of $\delta^{18} \mathrm{O}$ at Bern (Central Plateau) and Grimsel (inner cenrrai Ảps) is very similar, indicating a regional climatic signal. For the other months (except June and July) the isotopic ratio of precipitation was not significantly related to the tree ring series. This can be understood in terms of formation time for the latewood, which is during summer, although August might have been expected to exert some influence.

The results of the correlation analysis of the tree ring $\delta^{18} \mathrm{O}$ with climatic data from Bern are given in Table 2 . These calculations are based on a much longer period (1860-1997) than the above correlation with $\delta^{18} \mathrm{O}$ in precipitation. The most significant correlations are found for July, in agreement with the analysis of $\delta^{18} \mathrm{O}$ in precipitation. Temperature is positively correlated with tree ring $\delta^{18} \mathrm{O}$ (the slope of the regression line is $0.24 \% \mathrm{~d}^{\circ} \mathrm{C}$ ), whereas precipitation amount and relative humidity are negatively correlated. When calculating yearly means of the climate data, a significant relationship with the tree ring isotope curve still exists. This is also true for the means of the months May to August. This means that the tree ring curve does not only record information for July but also gives some indication of the climatic conditions during the whole growing season, in agreement with phenological observations. However, the correlation between the year-toyear variations of the climate parameters and the isotopes as given in Table 2 is quite low. This indicates that the short-term variations in $\delta^{18} \mathrm{O}$ of tree rings as well as in $\mathbf{s}^{18} \mathrm{O}$ of $\bar{p}^{1}$ ecipipitation cannot be fully explained by tcmiperature and precipitation changes.

The correlation analysis of isotopes with climate was 
Table 2. Correlation Coefficients $r$ From the Correlation of Monthly Climate Data (Bern) With Single-Year Latewood $\delta^{18} \mathrm{O}$ values From Bettlachstock.

\begin{tabular}{llll}
\hline & Temperature & Precipitation & $\begin{array}{l}\text { Relative } \\
\text { Humidity }\end{array}$ \\
\hline January & -0.08 & -0.08 & -0.07 \\
February & 0.09 & -0.18 & -0.17 \\
March & 0.02 & -0.01 & 0.00 \\
April & 0.15 & -0.02 & -0.07 \\
May & $0.23^{*}$ & -0.01 & -0.08 \\
June & 0.08 & -0.17 & -0.20 \\
July & $0.29 \dagger$ & $-0.30 \dagger$ & $-0.32 \dagger$ \\
August & 0.11 & -0.06 & $-0.27^{*}$ \\
September & 0.09 & 0.07 & -0.08 \\
October & 0.18 & -0.09 & -0.06 \\
November & -0.07 & 0.05 & -0.03 \\
December & 0.03 & -0.01 & -0.09 \\
Mean of year & $0.24^{*}$ & -0.20 & $-0.24^{*}$ \\
Mean of May- & $0.31 \dagger$ & $-0.26 \dagger$ & $-0.31 \dagger$ \\
August & & & \\
\hline \multicolumn{2}{l}{ Corelation } & &
\end{tabular}

* Correlation $\mathrm{p}<0.01$

$\dagger$ Correlation $\mathrm{p}<0.001$.

undertaken for several meteorological stations in the vicinity of the tree site. We wished to check the representativeness of the station with the longest record (Bern) in relation to stations closer to the tree site (Figure 1). The correlation coefficients between tree ring $\delta^{18} \mathrm{O}$ and the meteorological data at Bern are similar to those from Basel $(r=0.27$ for July temperature, $r=-0.26$ for July precipitation, and $r=-0.41$ for July relative humidity), Langenbruck $(r=0.40$, -0.32 , and -0.16 , respectively), Balmberg $(r=0.30,-0.26$, and -0.09 , respectively), Mt. Soleil $(r=0.40,-0.44$, and -0.20 , respectively), Biel ( $r=0.26,-0.29$, and -0.35 , respectively), Neuchatel ( $r=0.32,-0.31$, and -0.29 , respectively). The highest correlation between isotopes and climate was found for Mt. Soleil, a station at $1180 \mathrm{~m}$ asl and therefore at a similar elevation as Bettlachstock (1150 $\mathrm{m}$ asl).

We calculated the 10-year running mean of the tree ring isotope curve to investigate the long-term variations (Figures $2 a$ and $4 a$ ). The graph reveals a striking feature: a slow, quasi-periodic variation. This is confirmed by spectral analysis (Figure 5), which gives a highly significant peak at 24 years. A second peak at 10 years is also present (not significant). In Figure 4 the 10-year means of the climate variables are shown for comparison. These are calculated from the July data because of the high correlation found in the single-year analysis for this month. The longterm variations of the July temperature and the $\delta^{18} \mathrm{O}$ are very similar, although the temperature curve appears to slightly lag behind the isotope curve. Owing to this (variable) time lag the correlation between temperature and $\delta^{18} \mathrm{O}$ is quite low $(r=0.27)$, in contrast to the visual impression, which suggests a high degree of common variance. Furthermore, precipitation amount and relative humidity are related to the isotope variations during some periods, whereby dry periods (low precipitation and low humidity) are coinciding with high $\delta^{18} \mathrm{O}$ values.

\section{Discussion}

\subsection{Factors Influencing $\delta^{18} O$ in Tree Rings}

This discussion focuses on two questions: (1) What causes the variations in tree ring $\delta^{18} \mathrm{O}$ of Abies alba at the Bettlachstock site, and (2) what is the reason for the longterm (decadal scale) variation in $\delta^{18} \mathrm{O}$ ? Related to the first question, an important consideration is whether biological factors have a significant impact on the $\delta^{18} \mathrm{O}$ in the tree rings, thus potentially masking a climatic signal. It can also be asked whether tree rings are a reliable archive for $\delta^{18} \mathrm{O}$ in precipitation. Biological factors are important because of isotope fractionation during incorporation of the oxygen into the organic material, ranging from soil water uptake to leaf water enrichment, to biochemical fractionation in the leaf chloroplast and to the isotope exchange of intermediate products of photosynthesis with stem water during production of cellulose in the tree ring. Further, such factors might change from tree to tree and with the age of the tree, as well as from site to site, thereby introducing a variation which is not related to climate.

Our results strongly suggest that the latewood tree ring $\delta^{18} \mathrm{O}$ of Abies alba is recording the $\delta^{18} \mathrm{O}$ in precipitation. During the calibration period 1972-1992 (where data for $\delta^{18} \mathrm{O}$ in precipitation are available), there is a highly significant relation for the months of June and July. The high correlation for this period of the year may be explained by latewood largely being formed during this time. It is interesting to note that a correlation with an earlier period of the season (May to June) was found for a study based on whole-ring analysis of beech trees in the same region [Saurer et al., 1997a]. This indicates that potentially, a time resolution below 1 year can be achieved for $\delta^{18} \mathrm{O}$ reconstruction by splitting the tree rings. Earlywood might give information about the season when it is formed (spring) and latewood about summer. Usually, the isotope ratio in earlywood is thought to be less suited for climate reconstruction because the growth is mainly determined by reserves from the previous year [Robertson et al., 1997]. However, the reserves may influence the carbon isotopes more. The oxygen isotopes in earlywood are influenced by current conditions because of the isotope exchange of the storage carbohydrates with stem water [Hill et al., 1995]. We find a highly significant correlation between $\delta^{18} \mathrm{O}$ variations in tree rings and July temperature (Table 2). Although a correlation with June would have been expected as well (based on the correlation with $\delta^{18} \mathrm{O}$ in precipitation discussed above), this again indicates that tree rings are a reliable archive for $\delta^{18} \mathrm{O}$ in precipitation. The slope of the regression line is quite low $\left(0.24 \% d^{\circ} \mathrm{C}\right)$ compared to the slope values of between 0.5 and $0.9 \% /^{\circ} \mathrm{C}$ reported by Rozanski et al. [1992] for the temporal relation between temperature and $\delta^{18} \mathrm{O}$ in precipitation over the last 20 years. This reduced sensitivity is difficult to explain. It should also be noted that the coefficients reported by Rozanski et al. [1992] are based on long-term (annual) values, whereas the tree ring signal represents the summer precipitation only. Calculations with IAEA data from Bern showed that the June/July $\delta^{18} \mathrm{O}$ of precipitation and the June/July temperature are not significantly correlated dur- 

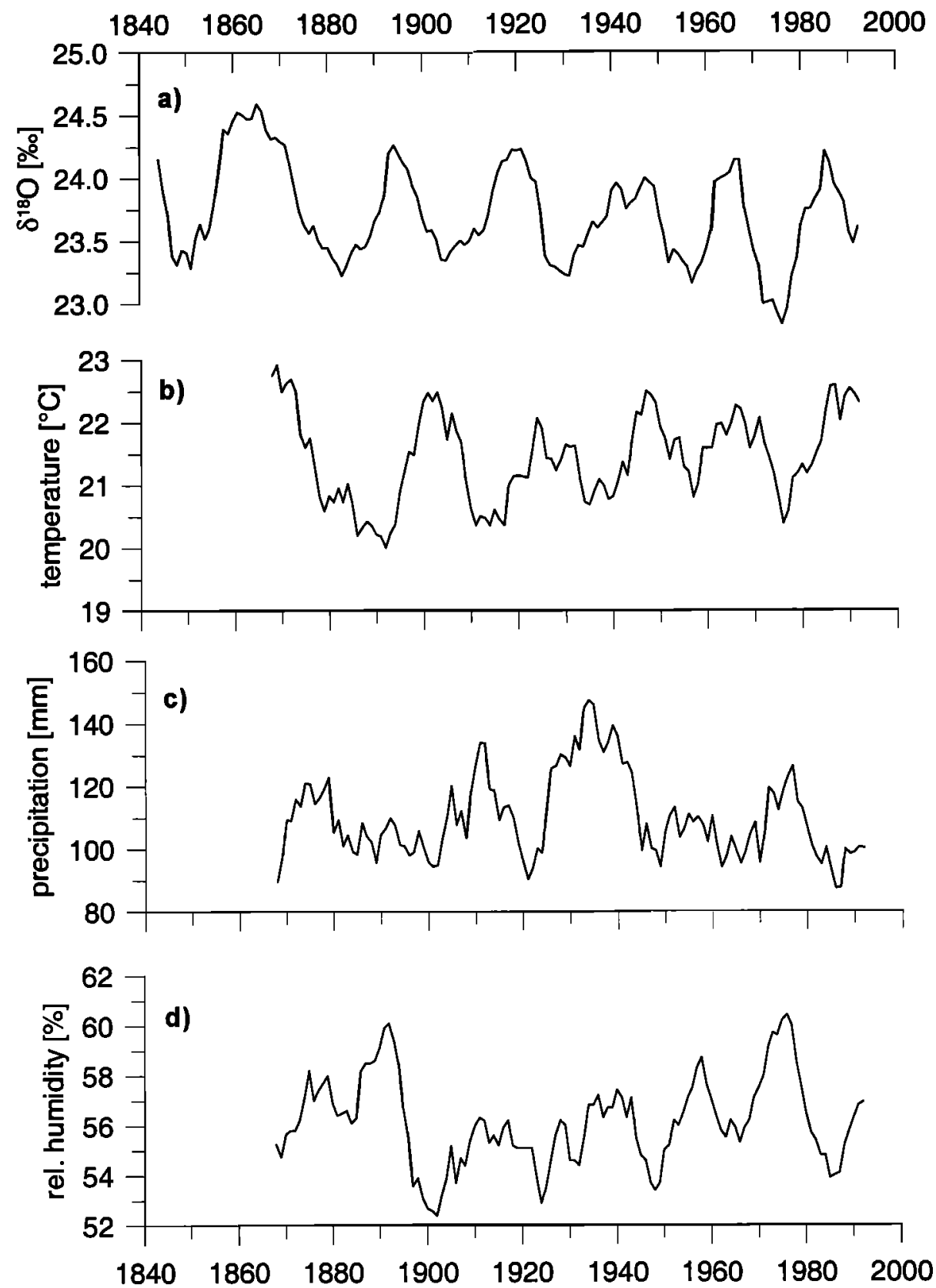

Figure 4. (a) 10-year running mean of the latewood $\delta^{18} \mathrm{O}$ chronology from Bettlachstock (Abies alba). (b) 10-year running mean of the July temperature (Bern). (c) 10-year running mean of the July precipitation (Bern). (d) 10-year running mean of the July air relative humidity (Bern).

ing the period from 1972 to 1992 . This makes evident that $\delta^{18} \mathrm{O}$ variations in precipitation cannot be explained by temperature alone. The finding that there is a significant influence of the July precipitation amount and the relative humidity on the tree ring $\delta^{18} \mathrm{O}$ (Table 2) further supports this conclusion.

The comparison of the Bettlachstock chronology with other series from the same region can be regarded as a further test to assess whether biological factors can be excluded as the cause for variations in $\delta^{18} \mathrm{O}$ (Table 1). It is very encouraging to find significant correlations with other series even when these involved different tree species (Fagus sylvatica, Picea abies), different material (whole year/cellulose), and differing site conditions. In our opinion, this clearly suggests that the $\delta^{18} \mathrm{O}$ in tree rings is to a large extent physically determined, despite a shift in the isotope ratio between soil water and organic material being observed. The physical factors include the $\delta^{18} \mathrm{O}$ in soil water and the evaporative leaf water enrichment. From the correlation analysis with the climate data (Table 2), we 


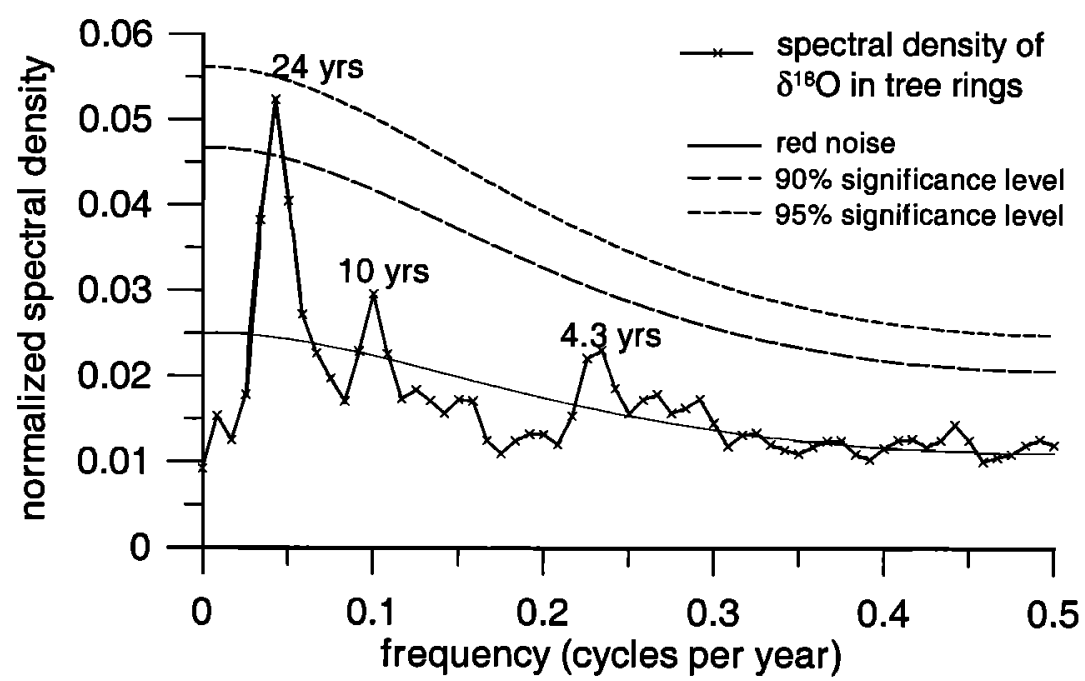

Figure 5. Normalized spectral density of the $\delta^{18} \mathrm{O}$ tree ring series showing a significant period at 24 years.

know that the tree ring $\delta^{18} \mathrm{O}$ is inversely related to the relative humidity of the atmosphere. This indicates that a "leaf water signal" is reflected in the tree rings because relative humidity is the driving force in the commonly used leaf water enrichment model according to Dongmann et al. [1974]. Nevertheless, the slope of the regression line $(-0.052 \% d \%$ for July) is not large enough to match the model value $(-0.36 \%$ o $\%$; estimated according to Saurer et al. [1997b]), meaning that the leaf water signal is strongly dampened in the tree ring. This is probably caused by two effects in combination, namely, (1) reduced enrichment in the chloroplast water compared to the sites of evaporation [Yakir et al., 1990] and (2) the isotope exchange with unenriched xylem water in the stem [Saurer et al, 1997b]. The dampening effect has also been found in another recent study [Aucour et al., 1996]. The high correlation with $\delta^{18} \mathrm{O}$ in precipitation suggests that the influence of relative humidity cannot be large.

We saw no age effects in the oxygen isotope ratios in the tree rings. The carbon isotope ratio often increases over the first 20-50 years of a tree's life [Francey and Farquhar, 1982]. Such a trend would indicate a biological, nonclimatic effect, but it is not present in our data. The slow, interdecadal variation of $\delta^{18} \mathrm{O}$ in our tree ring series might be related to some growth variations of the trees rather than a climatic signal. Rhythmic growth fluctuations have been reported for a large number of trees in Switzerland [Schweingruber et al., 1990], although the reason is not well understood. These growth variations were similar to $\delta \mathrm{D}$ fluctuations in spruce trees from south Germany reported by Lipp et al. [1992], which showed a period of $\sim 14$ years. However, for the tree ring width series of the trees at our study site, neither a rhythmic variation nor any similarities with the $\delta^{18} \mathrm{O}$ curve were found. We therefore believe that growth variations cannot be the cause of the longterm variations in $\delta^{18} \mathrm{O}$ in the tree rings.

An important result of our study is that the $\delta^{18} \mathrm{O}$ of whole wood may be as good a climate proxy as cellulose. After the recent development of continuous flow isotope ratio mass spectrometry for oxygen analysis, sample preparation is now the time-limiting step for the construction of long chronologies. When the tedious procedure of cellulose extraction is omitted, as also proposed for $\delta^{13} \mathrm{C}$ [Borella et al., 1998], then the oxygen isotope analysis of tree rings may be more widely applied. A similar conclusion was also drawn from a study where the $\delta^{18} \mathrm{O}$ of wood and the $\delta^{18} \mathrm{O}$ of the cellulose extracted from the same wood was compared for a number of tree rings [Borella et al., 1999]. The use of whole wood, however, involves some disadvantages compared to cellulose because of potentially varying amounts of constituents (with differing oxygen isotope ratio), as well as because of mobile compounds such as resins. Clearly, the method has to be carefully tested for other tree species. In particular, species with a high resin production might necessitate an extraction procedure with a solvent prior to the isotope analysis.

\subsection{Climatic Significance of the Long-Term Variations of $\delta^{18} \mathrm{O}$}

We have detected a slow, quasi-periodic variation of $\delta^{18} \mathrm{O}$ in the tree rings with a period of around 24 years (Figures 4 and 5), and considering the above discussion, it is likely that the same variation has occurred in $\delta^{18} \mathrm{O}$ in summer precipitation in Switzerland. To explain these variations, we have sought a correlation with summer temperature. There is a significant positive correlation with July temperature (Table 2), and also, the long-term variations in $\delta^{18} \mathrm{O}$ and temperature are similar (Figure 4). These findings confirm that the oxygen isotope ratio is a useful indicator of past temperatures on different timescales. Nevertheless, considerable uncertainty remains in the interpretation of $\delta^{18} \mathrm{O}$ : First, the explained variance of the temperature- $\delta^{18} \mathrm{O}$ relation is rather small (Table 2), and second, the overall trend in $\delta^{18} \mathrm{O}$, which is slightly decreasing at a rate of $-0.0032 \%$ o/yr (equivalent to $-0.32 \%$ in 100 years), apparently is contradicted by the increase in July temperature of $0.0031^{\circ} \mathrm{C} / \mathrm{yr}\left(0.31^{\circ} \mathrm{C}\right.$ in 100 years $)$ during the same period (1860-1997). Further, it is difficult to determine independently the effects of precipitation amount and relative humidity on the isotope ratio because the different climatic parameters are strongly correlated to each other. 
Rhythmic long-term variations in climatic parameters have also been found for other meteorological stations in the area (e.g., Basel), being most pronounced for the Grand Saint Bernard (see Figure 1). Here a periodicity with a period of $\sim 30$ years was found, with a clear negative correlation between temperature and precipitation [Wanner et al., 1997]. Such long-term variations could be caused by changes in large-scale atmospheric circulation, which are known to be related to climatic change. Climate in Switzerland, north of the Alps, is influenced by the North Atlantic, in particular, by the flow fields generated by the Icelandic low in the northwest and the Azores high in the southwest. Interdecadal- to century-scale changes of climate and atmospheric circulation could be caused by internal fluctuations of the climate system or could be triggered by external effects, such as solar variations (see below). Internal fluctuations are likely to occur because of ocean dynamics and related changes in the hydrosphere. For the North Atlantic the thermohaline circulation (deep water formation) is a sensitive element of the climate system [Stocker, 1996], and any decrease or increase greatly affects climate in Europe.

Regarding long-term variation of atmospheric circulation patterns, a well-known feature is the NAO, which is related to the pressure difference between Iceland and the Azores. Relatively high NAO indices imply a strong zonal (westerly) flow [Wanner et al., 1997]. Changes in the NAO can be expected to influence $\delta^{18} \mathrm{O}$ in precipitation in central Europe as the source and the flow path of the moisture are changed. We find a significant, although weak, correlation between the yearly averaged NAO index and our tree ring $\delta^{18} \mathrm{O}$ series $(r=0.24$ and $p<0.01$; NAO indices from Jones et al. [1997]). Regarding the century-scale trend, McKenzie and Hollander [1993] found decreasing $\delta^{18} \mathrm{O}$ over the last 200 years in lake sediments in Switzerland and concluded that the flow pattern for atmospheric moisture may have changed from southwest to northwest, affecting the isotope ratio of precipitation.

Periodic variations of climatic parameters have often been related to external factors. On a very long timescale these are, in particular, the Earth's orbital arrangements (Milankovitch's theory of the ice ages) and, on a shorter time scale, e.g., the 11-year sunspot cycle [Schove, 1983]. The relationships between tree ring data (ring widths) and sunspots have long been investigated, but no evidence of significant and consistent correlation has been found [LaMarche and Fritts, 1972]. The Hale cycle is another well-known cycle which is also related to disturbances of the Sun (magnetic polarity reversal of the sunspots). This cycle exhibits a period length of 22-23 years, thus in the same range as found in our tree ring $\delta^{18} \mathrm{O}$ series. Whereas the cycle is undoubtedly a physical reality, it is not easy to demonstrate the effect of this cycle on the Earth's climate [Fairbridge, 1984]. Nevertheless, in many climatic records, periodicities around 25 years have been found, particularly in Europe. However, these periodicities are not necessarily caused by external forcing [Lamb, 1972]. Some examples for parameters varying with a 20-25 year period given by Lamb [1972] include the pressure difference in January and July for westcrly winds over Britain and for southerly winds over the North Sea, the pressure difference in January between Madeira and Iceland and between
Siberia and Iceland, precipitation amount at several European stations and the maximum area of ice formed on the Baltic Sea. However, since the underlying time series are too short ( $150-300$ years), it is not possible to decide whether these phenomena are really cyclic.

\section{Conclusions}

Our data indicate that the oxygen isotope variations in tree rings are to a large degree physically determined despite large fractionation between soil water and organic matter and that biological factors, such as growth variations or ageing, are of minor importance. We thus find latewood $\delta^{18} \mathrm{O}$ of $\mathrm{Abies}$ alba to be a reliable archive for $\delta^{18} \mathrm{O}$ in summer precipitation, confirming results from other species. We find temperature to be an important determinant of the $\delta^{18} \mathrm{O}$ variations, whereby this holds for year-to-year as well as for decadal-scale variations. There are periodic changes in $\delta^{18} \mathrm{O}$ which could be caused by large-scale changes in the atmospheric circulation pattern over Europe and the North Atlantic Ocean. Furthermore, we conclude from our data that the analysis of whole wood instead of cellulose may well be justified for climate reconstruction. This finding in combination with the rapid development in continuous flow oxygen isotope analysis should foster the more widespread application of the method and enable the development of long $\delta^{18} \mathrm{O}$ chronologies in the future.

Acknowledgments. This research was partially funded by the Swiss Long-Term Forest Ecosystem Research. We thank Roberto Gonfiantini (Institute of Geochronology, CNR, Pisa) for stimulating discussion and John Innes (WSL, Birmensdorf) for supporting this project and for helpful comments on a previous draft. The comments by three anonymous reviewers helped to improve the manuscript.

\section{References}

Anderson, W.T., S.M. Bemasconi, J.A. McKenzie, and M. Saurer, Oxygen and carbon isotopic record of climate variability in tree-ring cellulose (Picea abies): An example from central Switzerland (1913-1995), J. Geophys. Res., 103(D24), 31,625-31,636, 1998.

Aucour, A.-M., C. Hillaire-Marcel, and R. Bonnefille, Oxygen isotopes in cellulose from modern and Quatemary intertropical peatbogs: Implications for palaeohydrology, Chem. Geol., 129, 341-359, 1996.

Borella, S., M. Leuenberger, M. Saurer, and R. Siegwolf, Reducing uncertainties in $\delta^{13} \mathrm{C}$ analysis of tree rings: Pooling, milling, and cellulose extraction, J. Geophys. Res., 103(D16), 19,519-19,526, 1998.

Borella, S., M. Leuenberger, and M. Saurer, Analysis of $\delta^{18} \mathrm{O}$ in tree rings: Wood-cellulose comparison and method dependent sensitivity, J. Geophys. Res., 104(D16), 19,267-19,273, 1999.

Burk, R.L., and M. Stuiver, Oxygen isotope ratios in trees reflect mean annual temperature and humidity, Science, 211, 1417$1419,1981$.

Dansgaard, W., Stable isotopes in precipitation, Tellus, Ser. B, $16,436,1964$.

Dongmann, G., H.W. Nürnberg, H. Förstel, and K. Wagener, On the enrichment of $\mathrm{H}_{2}{ }^{18} \mathrm{O}$ in the leaves of transpiring plants, Radiat. Environ. Biophys., $11,41-52,1974$.

Edwards, T.W.D., and P. Fritz, Assessing meteoric water composition and relative humidity from ${ }^{18} \mathrm{O}$ and ${ }^{2} \mathrm{H}$ in wood cellulose: Paleoclimatic implications for southern Ontario, Canada, Appl. Geochem., 1, 715-723, 1986.

Fairbridge, R.W., Planetary periodicities and terrestrial climate stress, in Climatic Changes on a Yearly to Millennial Basis, 
edited by N.-A. Mömer and W. Karlén, pp. 509-520, D. Reidel, Norwell, Mass., 1984.

Farquhar, G.D., and J. Lloyd, Carbon and oxygen isotope effects in the exchange of carbon dioxide between terrestrial plants and the atmosphere, in Stable Isotopes and Plant CarbonWater Relations, edited by J.R. Ehleringer, A.E. Hall, and G.D. Farquhar, pp. 47-70, Academic, San Diego, Calif., 1993.

Flanagan, L.B., J.P. Comstock, and J.R. Ehleringer, Comparison of modelled and observed environmental influences on the stable oxygen and hydrogen isotope composition of leaf water in Phaseolus vulgaris L., Plant Physiol., 96, 588-596, 1991.

Francey, R.J., and G.D. Farquhar, An explanation of ${ }^{13} \mathrm{C} /{ }^{12} \mathrm{C}$ variations in tree rings, Nature, 297, 28-31, 1982.

Hill, S.A., J.S. Waterhouse, E.M. Field, V.R. Switsur, and T. Aprees, Rapid recycling of triose phosphates in oak stem tissue, Plant Cell Environ., 18, 931-936, 1995.

Hoefs, J., Stable Isotope Geochemistry, 3rd ed., 241 pp., Springer-Verlag, New York, 1987.

International Atomic Energy Agency/World Meteorological Organization (IAEA/WMO), Global network for isotopes in precipitation, GNIP Database, Vienna, Release 2, May 1998.

Jones, P.D., R. Marsh, T.M.L. Wigley, and D.A. Peel, Decadal timescale links between Antarctic Peninsula ice-core oxygen18, deuterium and temperature, Holocene, 3,14-26, 1993.

Jones, P.D., T. Jónsson, and D. Wheeler, Extension to the North Atlantic Oscillation using early instrumental pressure observations from Gibraltar and South-West Iceland, Int. J, Climatol., 17, 1433-1450, 1997.

Jouzel, J., et al., Validity of the temperature reconstruction from water isotopes in ice cores, J. Geophy. Res., 102(C12), 26,471-26,487, 1997.

LaMarche, V., Jr., and H.C. Fritts, Tree-rings and sunspot numbers, Tree Ring Bullet., 32, 19-33, 1972.

Lamb, H.H., Climate: Present, Past and Future, vol.1, 613 pp., Methuen, London, 1972.

Lipp, J., P. Trimborn, and B. Becker, Rhythmic $\delta \mathrm{D}$ fluctuations in the tree-ring latewood cellulose of spruce trees (Picea abies L.), Dendrochronologia, 10, 9-22, 1992.

McKenzie, J.A., and D.J. Hollander, Oxygen-isotope record in recent carbonate sediments from Lake Greifen, Switzerland (1750-1986): Application of continental isotopic indicator for evaluation of changes in climate and atmospheric circulation patterns, in Climate Change in Continental Isotopic Records, Geophys. Monogr. Ser., vol. 78, edited by P.K. Swart et al., pp. 101-111, AGU, Washington, D. C., 1993.

Robertson, I., V.R. Switsur, A.H.C. Carter, A.C. Barker, J.S. Waterhouse, K.R. Briffa, and P.D. Jones, Signal strength and climate relationships in ${ }^{13} \mathrm{C}^{12} \mathrm{C}$ ratios of tree ring cellulose from oak in east England, J. Geophys. Res., 102(D16), 19,507-19,516, 1997.

Rozanski, K., L. Araguas-Araguas, and R. Gonfiantini, Long- term trends of oxygen-18 isotope composition of precipitation and climate, Science, 258, 981-985, 1992.

Rozanski, K., L. Araguas-Araguas, and R. Gonfiantini, Isotopic patterns in modern global precipitation, in Climate Change in Continental Isotopic Records, Geophys. Monogr. Ser., vol. 78, edited by P.K. Swart et al., pp. 1-37, AGU, Washington, D. C., 1993 .

Saurer, M., S. Borella, and M. Leuenberger, $\delta^{18} \mathrm{O}$ of tree rings of beech (Fagus sylvatica) as a record of $\delta^{18} \mathrm{O}$ of the growing season precipitation, Tellus, Ser. B., 49, 80-92, 1997a.

Saurer, M., K. Aellen, and R. Siegwolf, Correlating $\delta^{13} \mathrm{C}$ and $\delta^{18} \mathrm{O}$ in cellulose of trees, Plant Cell Environ., 20, 1543-1550, $1997 \mathrm{~b}$.

Saurer, M., I. Robertson, R. Siegwolf, and M. Leuenberger, Oxygen isotope analysis of cellulose: An inter-laboratory comparison, Anal. Chem., 70, 2074-2080, 1998.

Schönwiese, C.D., Praktische Statistik, pp. 231, Borntraeger, Berlin, 1992.

Schove, D.J., Sunspot cycles, Benchmark, vol. 38, pp. 397, Van Nostrand Reinhold, New York, 1983.

Schweingruber, F., K. Aellen-Rumo, U. Weber, and U. Wehrli, Rhythmic growth fluctuations in forest trees of central Europe and the Front Range of Colorado, Trees, 4, 99-106, 1990.

Sternberg, L. da S.L.O., and M.J. DeNiro, Biogeochemical implications of the isotopic equilibrium fractionation factor between the oxygen atoms of acetone and water, Geochim. Cosmochim. Acta, 47, 2271-2274, 1983.

Stocker, T., An overview of century time-scale variability in the climate system: Observations and models, in Decadal Climate Variability: Dynamics and Predictability, Proc. NATO Adv. Study Inst., vol.44, edited by D.L.T. Anderson and J. Willebrand, pp. 379-406, Springer, Berlin, 1996.

Wanner, H., R. Rickli, E. Salvisberg, C. Schmutz, and M. Schuiepp, Global climate change and variability and its influence on Alpine climate, Theor. Appl. Climatol., 58, 221-243, 1997.

Yakir, D., M.J. DeNiro, and J.R. Gat, Natural deuterium and oxygen-18 enrichment in leaf water of cotton plants grown under wet and dry conditions: Evidence for water compartmentation and its dynamics, Plant Cell Environ., 13, 49-56, 1990.

P. Cherubini, Swiss Federal Institute for Forest, Snow and Landscape Research, CH- 8903 Birmensdorf, Switzerland.

M. Saurer, and R. Siegwolf, Paul Scherrer Institute, CH-5232 Villigen PSI, Switzerland. (matthias.saurer@psi.ch)

(Received June 30, 1999; revised October 14, 1999; accepted February 29, 2000.) 